\title{
Factors associated with comorbidity patterns in full and partial PTSD: findings from the PsyCoLaus study
}

\author{
Mario Müller ${ }^{1^{*}}$, Caroline Vandeleur ${ }^{2}$, Stephanie Rodgers ${ }^{1}$, Wulf Rössler ${ }^{1,3,4}$, Enrique \\ Castelao ${ }^{2}$, Martin Preisig ${ }^{2}$, Vladeta Ajdacic-Gross ${ }^{1}$
}

\author{
${ }^{1}$ Department of Psychiatry, Psychotherapy and Psychosomatics, Zurich University Hospital of \\ Psychiatry, Switzerland \\ ${ }^{2}$ Department of Psychiatry, CHUV, Lausanne, Switzerland \\ ${ }^{3}$ Collegium Helveticum, University of Zurich and Swiss Federal Institute of Technology, \\ Zurich, Switzerland \\ ${ }^{4}$ Institute of Psychiatry, University of Sao Paulo, Brasil
}

Word count Abstract: 200

Word count text body: 4'104

Number of Tables: 5

Number of Figures: 1

${ }^{*}$ Corresponding author:

Mario Müller, PhD

Zurich University Hospital of Psychiatry

Department of Psychiatry, Psychotherapy and Psychosomatics

PO Box 1930

$\mathrm{CH}-8021$ Zurich

Switzerland

Tel: 0041-44-296 7432

Fax: 0041-44-296 7449

E-mail: mario.mueller@dgsp.uzh.ch 


\begin{abstract}
Subtypes of comorbid conditions and their associated trauma and clinical characteristics in full and partial PTSD were examined. Data from 289 subjects from the general population that met criteria for full or partial PTSD were analyzed. Latent class analyses (LCA) were performed to derive homogeneous patterns of DSM-IV Axis-I disorders and anti-social personality comorbid to PTSD. Logistic regression models were conducted to characterize these classes by trauma-related and clinical features. The LCA revealed three classes: (1) low comorbidity; (2) high comorbidity with primarily substance-related disorders and a higher proportion of males; and (3) more severe PTSD-symptomatology and higher comorbid anxiety disorders and depression, almost entirely represented by females. Exposure of sexual abuse was more likely in the substance-dependent class and contributed strongly to the distinction between classes. Affective disorders tended to precede the onset of PTSD in the substance-dependent class, whereas phobias were more likely to follow PTSD in the depressed-anxious class. Posttrauma onset of alcohol use disorders in the substance dependent class confirmed the self-medication hypothesis. The three classes of comorbidity and their sequence of onset with PTSD suggest different mechanisms involved in their development. Our findings suggest that PTSD-related comorbidity subtypes also apply to individuals with partial PTSD.
\end{abstract}

Keywords: Full and partial PTSD, comorbidity, subtyping, trauma type, latent class analysis 


\section{Introduction}

Traumatic stress exposure might place an individual at increased risk for a broad range of psychiatric disorders. From those, posttraumatic stress disorder (PTSD) may be the most common condition. Frequent co-occurring conditions are anxiety, mood and substancerelated disorders as well increased rates of suicidality [1-6]. In a review, Breslau (2009) estimated that individuals with PTSD tend twice as likely to have another psychiatric disorder compared to those without the syndrome. Prevalence rates of disorders comorbid with PTSD in community samples ranged between 50 and 100\% [7]. Epidemiological studies have suggested that comorbidity among individuals with PTSD is associated with a more severe clinical profile, worse course and greater impairment and disability $[8,9]$. Thus, psychiatric comorbidity in PTSD could be an indicator for the severity of the disorder, although the reverse might be possible as well [10].

Previous research revealed gender, socioeconomic status and other demographic features as well as common genetic and environmental factors to account for the co-occurrence of PTSD with other disorders [11-14]. Especially source and type of trauma were linked to specific comorbidities in previous studies (review: [3]. For example, combat-related PTSD was highly associated with comorbid substance-related disorders, depressive and personality disorders [15] while sexual dysfunction and substance-related disorders were highly prevalent after the experience of childhood or sexual trauma [16-19]. Victims of physical violence were found to be at risk for co-occurring anxiety disorders and depression [20] while phobic disorders and depression as comorbid conditions to PTSD are frequently linked to the experience of a disaster [21].

However, existing studies are mostly limited by their methods exploring the comorbid complexity of PTSD, since standard methods that simply assess the association with another single disorder simultaneously make a holistic picture of comorbidity patterns elusive. According to a more comprehensive approach using latent class analysis, comorbidity in PTSD appeared to take three different forms [10]. The first class grouped individuals with low comorbidity levels and a moderate probability of lifetime major depression and suicidality. 
The second class included subjects with higher comorbidities of suicidality as well as depressive and anxiety disorders, whereas the third class was characterized by subjects with high probable comorbid substance-related disorders [10].

Another shortcoming in most of the existing studies exploring PTSD comorbidity is the neglect of posttraumatic symptoms that fall short of the full diagnostic criteria of PTSD. Despite high rates of traumatic experiences in general population samples, only a few subjects will subsequently develop PTSD [22]. The diagnostic concept of partial PTSD was developed to account for subjects who have symptoms of PTSD but do not fulfill all diagnostic criteria. Partial PTSD might be the result of partial recovery from a full PTSD syndrome or the development of subthreshold symptoms after trauma exposure [23]. Nevertheless, there is empirical evidence that partial PTSD, and even the presence of single PTSD symptoms, is also associated with a wide array of comorbid disorders almost as large as for full PTSD [1]. Previous findings are, however, difficult to compare since no consensus on the definition of partial PTSD has been reached so far.

In the current study, we used a similar approach to the one used by Galatzer-Levy et al. (2013) but extended our population under study to those with partial PTSD. Accordingly, we focused on three aims: (i) to estimate the associations of trauma type and comorbid disorders with PTSD in a representative community sample; (ii) to identify subgroups of participants diagnosed with full or partial PTSD that have homogeneous profiles of comorbid disorders and suicidal behavior; and (iii) to examine the extent to which these different subgroups were characterized by different trauma-related and clinical features.

\section{METHOD}

\section{Sample and procedure}

All data were collected in the PsyCoLaus study, a subsample from the larger CoLaus study, a randomly selected population-based cohort study of Lausanne, i.e. in the French part of Switzerland. From 2003 to 2006 , a community sample of $\mathrm{N}=6,734$ subjects aged between 35 and 75 years was recruited for the first wave of CoLaus, an epidemiological study designed 
to assess the prevalence of cardiovascular risk factors and diseases. From a total of 5,535 individuals that finally participated in the CoLaus study, two thirds $(N=3,720 ; 67.00 \%)$ agreed to take part in the additional psychiatric (PsyCoLaus) assessment. From this sample, about half $(52.96 \%)$ were female and the mean age of the subjects was 49.60 years $(S D=8.80)$. For the present analyses $\mathrm{N}=26$ subjects $(0.70 \%)$ were excluded due to missing data on the screening item of exposure.

The study was approved by the Ethics Committee of the University of Lausanne, Switzerland. All participants provided written consent after being informed of the goal and funding of the study.

\section{Measures}

The data of the PsyCoLaus study were derived from the French version [24] of the semistructured Diagnostic Interview for Genetic Studies (DIGS) [25]. In addition to demographic features, the French version of the DIGS comprises information on a broad spectrum of DSM-IV Axis I and Axis II criteria as well as on suicide behavior [26]. PTSD and generalized anxiety disorders were assessed using the relevant sections from the French version [27] of the Schedule for Affective Disorders and Schizophrenia - Lifetime and Anxiety disorder version [28]. According to the definition of Breslau et al. [29], partial PTSD was defined as one or more symptom(s) in each of the three symptom clusters of PTSD (re-experience, avoidance/numbing, and hyperarousal) with a duration of at least one month. Exposure to potentially traumatizing events was assessed using five separate questions: 1.) accident, 2.) physical assault, 3.) combat and/or war, 4.) witness of murder, violence or death by an accident, and 5.) sexual abuse. Subsequently, all distinct events reported by the respondent were repeated by the interviewer and the respondent was asked to identify the most upsetting event and the age of first exposure to this event. Age of first sexual abuse was asked separately. All associations with single traumatic events are in relation to this specific event. 
The French version of the DIGS as well as the anxiety sections of the SADS-LA revealed excellent inter-rater and fair to good test-retest reliability for mood [30], substance use [31] and anxiety disorders [27]. The three-year test-retest reliability in terms of Yule's $Y$ coefficients for the PTSD diagnosis was 0.69 in a sample of 176 psychiatric patients [32]. Furthermore, the test-retest Yule's $Y$ coefficients for exposure to violent crime and sexual trauma in this sample were as high as 0.84 and 0.57 , respectively, although those for exposure to accidents and witnessing trauma to others were only 0.30 and 0.22 , respectively. The test-retest reliability for exposure to war could not be tested in this sample given its rareness [32].

The following categories, based on the DSM-IV criteria, were considered as comorbid conditions: alcohol use disorders (abuse or dependence), other substance-related disorders (abuse or dependence of cannabis, solvent, hallucinogens, stimulants, cocaine, sedativa, or narcotics), major depressive episode, dysthymia, generalized anxiety disorder (GAD), simple phobia, social phobia, agoraphobia, panic disorder, antisocial personality disorder, and suicide attempts.

\section{Statistical analysis}

The current analyses, based on cross-sectional data, were carried out in three steps.

First, bivariate associations between partial and/or full PTSD and types of traumatic exposure and comorbid conditions were established. Logistic regression models were calculated and odds ratios $(\mathrm{OR})$ with $95 \%$ confidence intervals $(95 \% \mathrm{Cl})$ were computed to examine differences among PTSD conditions.

Second, latent class analysis (LCA) was used to identify distinct patterns of comorbidity among subjects diagnosed with PTSD (full or partial). LCA is a person-centered approach that identifies homogeneous groups of individuals based on similarities of diagnostic patterns. LCA is well suited to explore possible sub-populations within a sample because it simultaneously evaluates all diagnoses submitted to the analysis and yields fit statistics that allow testing for multiple class solutions. Accordingly, starting with a single (all PTSD- 
diagnosed individuals) class solution, we tested solutions with increasing numbers of classes. We evaluated the relative fit of different models using the Bootstrapped Likelihood Ratio Test (BLRT; McLachlan and Peel, 2000), the Bayesian information criterion (BIC), the sample-size-adjusted BIC (BIC-A), the Akaike information criterion (AIC; [33], and the entropy measure [34]. Significant BLRT values suggest that a model is preferable over another model with the next lowest number of classes. A non-significant BLRT value indicates that the solution includes too many classes [35]. Lower values of BIC, AIC and BICA for a given model indicate an improved model fit relative to another model with more or less classes. Furthermore, entropy was considered as a measure of classification accuracy (with higher values indicating better classification).

In a third and final step, multinomial logistic regression models were calculated to estimate associations of comorbid disorders, their ages of onset as well as temporal associations with PTSD onset, with trauma and clinical features on PTSD subtypes derived using the LCA. Odds ratios and $95 \%$ confidence intervals were calculated for unadjusted and sex-ageadjusted models.

LCAs were conducted using MPlus v6 [36]. All other analyses were conducted using Stata/SE 12 [37].

\section{RESULTS}

Prevalence rates of trauma exposure and associations between types of trauma and PTSD

Rates for full, partial PTSD, and either condition were $3.98 \%, 3.84 \%$, and $7.82 \%$, respectively. PTSD occurred more frequently in females, in particular full PTSD. Age was not significantly associated with the occurrence of PTSD.

About one fifth $(22.23 \%)$ of the study sample was exposed to at least one lifetime traumatic event from which $3.65 \%$ experienced more than one trauma. The mean number of events was $.26(\mathrm{SD}=.54)$. As the most upsetting event, the majority reported witnessing a murder, 
violence or death by an accident (8.88\%), followed by a self-experienced accident $(4.36 \%)$, physical assault (3.25\%), sexual abuse (3.11\%), and finally exposure to combat and/or war $(1.54 \%)$. About seven percent $(6.74 \%)$ experienced trauma before the age of 16 , mostly of non-sexual nature $(4.52 \%)$, whereas $2.22 \%$ reported sexual abuse during childhood. Compared to males, females reported significantly more physical assault ( $4.24 \%$ vs. $2.13 \%$ : $\left.\mathrm{Chi}^{2}=13.01, \mathrm{p}<.001\right)$, sexual abuse $\left(5.06 \%\right.$ vs. $0.92 \%$ : $\left.\mathrm{Chi}^{2}=52.15, \mathrm{p}<.001\right)$, more childhood trauma $\left(8.43 \%\right.$ vs. $4.84 \%$ : $\left.\mathrm{Chi}^{2}=18.85, \mathrm{p}<.001\right)$, and childhood sexual abuse $(3.52 \%$ vs. $\left.0.75 \%: \mathrm{Chi}^{2}=32.65, \mathrm{p}<.001\right)$. Males experienced more war/combat-related trauma $(2.13 \%$ vs. 1.02\%: $\mathrm{Chi}^{2}=7.46, \mathrm{p}=.006$ ), witnessed more murder, violence or death by an accident (10.54\% vs. $\left.7.41 \%: \mathrm{Chi}^{2}=11.18, \mathrm{p}=.001\right)$. Those with sexual abuse $(47.41$ years; $\mathrm{SD}=7.51$ vs. 49.68 years; $\left.S D=8.83 ; p=.01: F_{(1 ; 3,692)}=7.39 ; p=.007\right)$ as well as childhood sexual abuse (47.52 years; $S D=7.89$ vs. 49.65 years; $S D=8.82 ; p=.03: F_{(1 ; 3,692)}=4.71 ; p=.030$ ) were significantly younger than their unexposed counterparts.

All types of trauma were significantly associated with partial PTSD, full PTSD and either of these conditions. Overall sexual abuse as well as its early exposure were most highly associated with PTSD (full and partial) and contributed significantly to the risk for full versus partial PTSD. Multiple exposures as well as the number of exposures were associated with an increased risk for full and partial PTSD, but did not distinguish between these conditions.

\section{Prevalence rates of comorbid disorders and their associations with PTSD}

Estimated lifetime prevalences of comorbid disorders are presented in Table 1 for the total sample and for those with PTSD (full and/or partial PTSD). Those with full or partial PTSD were most frequently diagnosed with comorbid major depressive disorder (33.22\%), followed by simple phobia $(26.64 \%)$, alcohol use disorders $(19.38 \%)$ and social phobia $(19.38 \%)$. About one fifth of those with full or partial PTSD reported at least one lifetime suicide attempt $(20.42 \%)$.

Full and partial PTSD were significantly associated with comorbid alcohol use disorders, major depressive episode, simple phobia, and suicide attempts. Full, but not partial PTSD, 
was associated with substance use disorders, GAD, social phobia, agoraphobia, panic and antisocial personality disorders. Dysthymia was associated with partial PTSD only. Suicide attempts, GAD, panic and antisocial personality disorders were significantly more frequent in full than in partial PTSD (see Table 1). The total number of comorbid conditions was more frequent in any PTSD condition, but were also more likely to occur in full versus partial PTSD.

- insert Table 1 -

\section{Latent class analysis of comorbid disorders among subjects with full or partial PTSD}

The LCA of those with either condition, full or partial PTSD $(\mathrm{N}=289)$, led to a three-class solution (see Figure 1) that fitted the data significantly better than a one- or two-class solution, while four or five-class solutions were not superior to the three-class solution (Table 2). Class $1(\mathrm{~N}=202)$ contains those PTSD cases with low comorbidity rates that are mostly similar to the total sample (alcohol use disorders and simple phobia) or even lower (substance-related disorders, dysthymia, agoraphobia, GAD, panic and antisocial personality disorders). Rates for suicide attempts, major depressive episodes and social phobia are slightly higher than in the total sample (compare prevalence rates of Tables $1 \& 3$ ). In contrast to that, classes 2 and 3 comprise those cases with higher overall numbers of comorbid disorders and suicide attempts as well as slightly higher rates of major depressive disorders (although not significantly different from class 1 ). Class $2(\mathrm{~N}=28)$ was specifically characterized by high rates of alcohol and substance use disorders, antisocial personality disorders as well as high rates of suicidal behavior. Class $3(\mathrm{~N}=59)$ was characterized by high rates of dysthymia and by highest proportions of all anxiety disorders and suicidal behavior. Accordingly, class 1 was labeled as "low comorbidity", class 2 as "high comorbidity substance dependent", and class 3 as "high comorbidity depressed-anxious".

- $\quad$ insert Figure 1 -

- insert Table 2 -

- insert Table 3 - 


\section{Predictors of comorbidity patterns in PTSD}

The substance-dependent class was more likely in males and in younger subjects when compared to low comorbidity (see Table 3). In contrast, the depressed-anxious class was almost fully represented by females and significantly older than the substance-dependent class. Furthermore, the substance dependent class was characterized by significantly earlier onset of substance (including alcohol) use and any anxiety disorder (i.e., combined GAD/panic disorders) than those with low comorbidity (see Table 4). Onset of alcohol use was more likely follow the onset of PTSD in the substance dependent class compared to low comorbidity. The depressed anxious class was further characterized by later onsets of phobias, especially social phobia, than the low comorbidity class and later onsets of PTSD, alcohol use and panic disorders compared to the substance dependent class. In the anxiousdepressed class onsets of any phobic disorder (i.e., either social, simple or agoraphobia) were more likely to follow the onset of PTSD while onsets of unipolar affective disorders (i.e. either major depressive disorder or dysthymia), significantly preceded the onset of PTSD when compared to the low comorbidity class.

- insert Table 4 -

Compared to the low comorbidity class, the high comorbidity classes were significantly associated with more PTSD reexperience and avoidance/numbing symptoms (see Table 5). Symptoms of hyperarousal were more pronounced in the depressed-anxious class compared to low comorbidity. The high comorbidity classes were linked to lower overall functioning than that with low comorbidity. Furthermore, the classes were associated with different trauma types. Accordingly, compared to the substance dependent class, the depressed-anxious class was more significantly represented by those exposed to physical assault; this association however, did not hold after adjusting for sex and age. In contrast, sexual abuse 
(overall and below age 16) was significantly more likely in the substance-dependent compared to the other classes.

- insert Table 5 -

\section{Discussion}

This study tested competing models for the latent structure of PTSD comorbidity using data from a population-based sample of individuals diagnosed with full or partial PTSD. We performed a LCA and compared competing models based on their fit indices. Accordingly, our findings suggested three latent classes of comorbid disorders in individuals with PTSD. The first and largest class, which we named "low comorbidity" contains those with few comorbid conditions, in particular lifetime major depressive episodes. However, major depressive episodes were basic features of all the classes derived from our data. This is consistent with a factor-analytic approach, in which PTSD loaded highly on a factor that was primarily defined by mood disorders [38]. Affective features have a high covariation with PTSD symptomatology (i.e., narrowed affectivity and foresight) and might therefore be seen as an integrative part of it [39, 40]. A recent review summarizing fifty-seven studies published between 1997 and 2012 estimated that about half (52\%) of the individuals with PTSD had a co-occurring major depressive disorder [41]. PTSD and major depression are assumed to be related to posttraumatic psychopathologies since the course of both disorders evolve in parallel, are predictive of each other and share a common set of predictors [42].

The second class (high comorbidity substance dependent) was characterized by a higher number of comorbid conditions compared to class one. The most specific characteristic of this class was the high occurrence of alcohol/substance-related disorders as well as antisocial personality disorders. This supports earlier research suggesting externalizing disorders to constitute a specific subtype of posttraumatic reactions $[38,43]$. According to this, those with externalizing disorders have a tendency to display their distress outwardly in the form of anger, aggressiveness and substance abuse, which include features of antisocial 
personality disorders [44]. Alcohol and other substance-related disorders are among the most common co-occurring disorders and there is evidence that PTSD generally precedes the onset of increased substance use [45]. According to the self-medication hypothesis of PTSD, traumatized individuals abuse substances in order to reduce distress-related symptoms and are at risk to maintain this behavior by a negative reinforcement resulting from symptom relief [43]. Although this class was characterized by a lower age of alcohol use disorder onset compared to the other classes, this onset was temporally situated after the onset of PTSD symptoms.

Finally, we found a third class (depressed anxious) that was primarily characterized by unipolar affective and anxiety disorders, especially phobic disorders. The high co-occurrence of PTSD, depression and other anxiety disorders has been highlighted by previous research $[9,46]$. Dimensional models of posttraumatic psychopathology suggested PTSD, unipolar depressive and anxiety disorders to constitute an internalizing dimension of posttraumatic reactions [38, 43]. Accordingly, internalizers are individuals who display their distress inwardly and therefore demonstrate high negative emotionality, which will be expressed by reactions of fear and misery [44]. Moreover, there is considerable overlap of diagnostic criteria, such as phobic and affective features of PTSD. For example, avoidance symptoms in anxiety disorders or insomnia, impaired concentration and narrowed foresight in depression might be interpreted as symptoms of PTSD, or vice versa $[39,40,47]$. Another explanation might be that the onset of one disorder influences the onset of the other disorder, i.e. depression or anxiety disorders precede the experience of a traumatic event and act as a potential vulnerability factor for PTSD, or vice versa $[39,48,49]$. Interestingly, in the anxiousdepressed class, affective disorders were more likely to precede PTSD while phobias rather tended to follow the onset of PTSD relative to those with less comorbidity. However, it might be an artifact of a somewhat smaller ratio between earlier and later onset than PTSD compared to other classes. On the other hand, this class is characterized by a much older age of phobia onset than other classes, which, however, was only significantly different from the low comorbidity class. This finding is contrary to the existing literature and requires 
further replication. One should clarify whether it describes specific mechanisms involved in the co-occurrence of these disorders or was simply coincidental.

Gender appeared to be a key aspect in the distinction between the high comorbidity classes of substance-dependent and anxious-depressive. While the latter was almost fully represented by females the former was notably overrepresented by males. This is consistent with the literature in so far as females are more likely to show internalizing trauma responses, such as anxiety and depression, while males are rather at risk to develop externalizing disorders, such as alcohol and/or substance use and antisocial personality disorders $[44,50])$. Our data further support earlier findings that higher comorbidity is linked to higher rates of suicide behavior $[6,10]$ especially when additional alcohol use or anxiety disorders were present $[47,51,52]$. This suggests more psychiatric burden. In fact, higher PTSD symptomatology and increased impairment, as indicated by lower global functioning, in classes 2 and 3 provide further evidence of greater comorbidity to co-occur with greater PTSD severity [10]. However, while symptoms of re-experience and avoidance were linked to both high comorbidity classes, symptoms of increased arousal were exclusively specific to the depressed-anxious class. This might be explained by symptom overlap between PTSD and other anxiety disorders. For example, already four of the five hyperarousal symptoms define criteria for GAD, while some avoidance symptoms are similar to those defining panic disorders. Individuals with anxiety disorders but unexposed to trauma often endorse those items while other symptoms, such as intrusions, are primarily related to a traumatic event and are rather specific for PTSD [53]. This has important implications for therapeutic interventions because subjects suffering from PTSD with comorbid anxiety disorders were found to recover more slowly than those without comorbid anxiety disorders [54]. Thus, high comorbidity with anxiety disorders entails an increased risk for chronification of PTSD compared to other comorbid conditions $[3,55,56]$.

All trauma types contributed significantly to the development of full and partial PTSD. Although the odds ratios were almost comparable for either condition, interpersonal traumatic experiences such as physical assault and sexual abuse had the greatest impact. Sexual 
abuse (overall and childhood) further doubled the risk for full PTSD compared to partial PTSD. This is in line with earlier research suggesting that interpersonal trauma has a greater impact on stress response syndromes in terms of illness severity and the amount of comorbid conditions [57]. In fact, sexual abuse as well as physical assault contributed significantly to the difference between high and low comorbidity. However, our results suggested that sexual abuse (overall and childhood) was specifically linked to the substance dependence (class 2) while physical assault was rather linked to the anxious-depressed class although this association did not hold after adjusting for gender and age. Therefore, it can be assumed that, depending on the source of trauma, specific etiological pathways may be involved. Indeed, the co-occurrence of PTSD and substance-related disorders was previously found to be associated with childhood adversities, especially sexual abuse [5860]. Thereby, the fact that more males than females are in this class appears contradictory, given the overall higher rates of sexual abuse among females [61]. However, this is in line with a previous study suggesting that males showed higher rates of substance abuse after exposure to child sexual abuse than females, irrespective of the exposure rates [62]. Alternatively, when considering a reversed causality, it might be possible as well that individuals who abuse drugs, who are predominantly males, are more likely to be exposed to environments with an increased risk of interpersonal violence (including sexual violence) [49]. This, at least, was not confirmed by our data when comparing age of first sexual abuse and disorder's onsets.

\section{Limitations}

A number of limitations of this study should be acknowledged. One of them is the crosssectional nature of our data. Thus, although self-report of traumatic experiences is commonly used in PTSD research, the data might be subject to recall bias, especially in those of older age. This also applies when considering temporal associations among trauma exposure, PTSD and comorbid conditions. However, it is hardly possible to obtain data from more reliable sources. On the other hand, we cannot exclude the possibility that the self-report of 
traumatic exposure, rather than exposure itself, was associated with a certain comorbidity profile. Finally, trauma exposure was assessed using rather broad categories of traumatizing events, which might have affected PTSD prevalences. Especially in community samples, when trauma status is a priori unknown, varying methods of trauma assessment might lead to different rates of trauma, which in turn, is highly linked to the prevalence of PTSD [32, 63].

\section{Conclusion}

Our study broadly contributes to the existing literature of PTSD comorbidity in terms of its multidimensional structure as well as its correlates, such as types of trauma. The identification of subtypes in PTSD comorbidity and their associated factors provides a more parsimonious theoretical context for stress response disorders. Whether different treatment methods should be used for different subtypes requires further investigation. However, the identification of specific factors linked to these subtypes as well as their different symptom expressions may help to understand etiological mechanisms and has important implications for identification, prevention and reduction of health risks among trauma victims [44]. Our findings further suggest that PTSD-related comorbidity subtypes are not limited to full PTSD, but may also apply to traumatized individuals that fall below the cutoff of full PTSD. Screening, prevention and intervention programs should also target those with less severe PTSD symptomatology to pre-estimate and reduce subsequent morbidity, mortality and the risk of suicidal behaviors. 


\section{References}

[1] Pietrzak RH, Goldstein RB, Southwick SM, Grant BF. Psychiatric comorbidity of full and partial posttraumatic stress disorder among older adults in the United States: results from wave 2 of the National Epidemiologic Survey on Alcohol and Related Conditions. Am J Geriatr Psychiatry. 2012;20:380-90.

[2] Javidi H, Yadollahie M. Post-traumatic Stress Disorder. Int J Occup Environ Med. 2012;3:2-9.

[3] Deering CG, Glover SG, Ready D, Eddleman HC, Alarcon RD. Unique patterns of comorbidity in posttraumatic stress disorder from different sources of trauma. Compr Psychiatry. 1996;37:336-46.

[4] Kessler RC, Sonnega A, Bromet E, Hughes M, Nelson CB. Posttraumatic stress disorder in the National Comorbidity Survey. Arch Gen Psychiatry. 1995;52:1048-60.

[5] Spitzer C, Barnow S, Volzke H, John U, Freyberger HJ, Grabe HJ. Trauma and posttraumatic stress disorder in the elderly: findings from a German community study. J Clin Psychiatry. 2008;69:693-700.

[6] Krysinska K, Lester D. Post-traumatic stress disorder and suicide risk: a systematic review. Arch Suicide Res. 2010;14:1-23.

[7] Köllner V, Maercker A. Das diagnostische Spektrum der Traumafolgestörungen. Bedeutung für die Therapie, praktisches Vorgehen und Ausblick auf mögliche Änderungen in ICD-11 und DSM-V. Trauma \& Gewalt. 2011;5:236-47.

[8] Quarantini LC, Netto LR, Andrade-Nascimento M, Almeida AG, Sampaio AS, Miranda-Scippa A, et al. [Comorbid mood and anxiety disorders in victims of violence with posttraumatic stress disorder]. Rev Bras Psiquiatr. 2009;31 Suppl 2:S66-76.

[9] Johansen VA, Eilertsen DE, Nordanger D, Weisaeth L. Prevalence, comorbidity and stability of post-traumatic stress disorder and anxiety and depression symptoms after exposure to physical assault: an 8-year prospective longitudinal study. Nord J Psychiatry. 2013;67:69-80.

[10] Galatzer-Levy IR, Nickerson A, Litz BT, Marmar CR. Patterns of lifetime PTSD comorbidity: a latent class analysis. Depress Anxiety. 2013;30:489-96.

[11] Ayazi T, Lien L, Eide AH, Ruom MM, Hauff E. What are the risk factors for the comorbidity of posttraumatic stress disorder and depression in a war-affected population? A cross-sectional community study in South Sudan. BMC Psychiatry. 2012;12:175.

[12] Sartor CE, McCutcheon VV, Pommer NE, Nelson EC, Grant JD, Duncan AE, et al. Common genetic and environmental contributions to posttraumatic stress disorder and alcohol dependence in young women. Psychol Med. 2011;41:1497-505.

[13] Auxemery Y. [Posttraumatic stress disorder (PTSD) as a consequence of the interaction between an individual genetic susceptibility, a traumatogenic event and a social context]. Encephale. 2012;38:373-80.

[14] Goenjian AK, Bailey JN, Walling DP, Steinberg AM, Schmidt D, Dandekar U, et al. Association of TPH1, TPH2, and 5HTTLPR with PTSD and depressive symptoms. J Affect Disord. 2012;140:244-52.

[15] Arbanas G. Patients with combat-related and war-related posttraumatic stress disorder 10 years after diagnosis. Croat Med J. 2012;51:20914.

[16] Khoury L, Tang YL, Bradley B, Cubells JF, Ressler KJ. Substance use, childhood traumatic experience, and Posttraumatic Stress Disorder in an urban civilian population. Depress Anxiety.27:1077-86.

[17] Khoury L, Tang YL, Bradley B, Cubells JF, Ressler KJ. Substance use, childhood traumatic experience, and Posttraumatic Stress Disorder in an urban civilian population. Depress Anxiety. 2010;27:1077-86. 
[18] Maniglio R. The role of child sexual abuse in the etiology of substance-related disorders. J Addict Dis. 2011;30:216-28.

[19] Postma R, Bicanic I, van der Vaart H, Laan E. Pelvic floor muscle problems mediate sexual problems in young adult rape victims. J Sex Med. 2013;10:1978-87.

[20] Johansen VA, Wahl AK, Eilertsen DE, Hanestad BR, Weisaeth L. Acute psychological reactions in assault victims of non-domestic violence: peritraumatic dissociation, post-traumatic stress disorder, anxiety and depression. Nord J Psychiatry. 2006;60:452-62.

[21] Meewisse ML, Olff M, Kleber R, Kitchiner NJ, Gersons BP. The course of mental health disorders after a disaster: predictors and comorbidity. J Trauma Stress. 2011;24:405-13.

[22] Breslau N. The epidemiology of trauma, PTSD, and other posttrauma disorders. Trauma Violence Abuse. 2009;10:198-210.

[23] Marshall RD, Olfson M, Hellman F, Blanco C, Guardino M, Struening EL. Comorbidity, impairment, and suicidality in subthreshold PTSD. Am J Psychiatry. 2001;158:1467-73.

[24] Leboyer M, Barbe T, Gorwood P, Teherani M, Allilaire JF, Preisig M, et al. Interview diagnostique pour les études génétiques. Paris: Institut National de la Santé et de la Recherche Médicale; 1995.

[25] Nurnberger JI, Jr., Blehar MC, Kaufmann CA, York-Cooler C, Simpson SG, Harkavy-Friedman J, et al. Diagnostic interview for genetic studies. Rationale, unique features, and training. NIMH Genetics Initiative. Arch Gen Psychiatry. 1994;51:849-59; discussion 63-4.

[26] Preisig M, Waeber G, Vollenweider P, Bovet P, Rothen S, Vandeleur C, et al. The PsyCoLaus study: methodology and characteristics of the sample of a population-based survey on psychiatric disorders and their association with genetic and cardiovascular risk factors. BMC Psychiatry. 2009;9:9.

[27] Leboyer M, Maier W, Teherani M, Lichtermann D, D'Amato T, Franke P, et al. The reliability of the SADS-LA in a family study setting. Eur Arch Psychiatry Clin Neurosci. 1991;241:165-9.

[28] Endicott J, Spitzer RL. A diagnostic interview: the schedule for affective disorders and schizophrenia. Arch Gen Psychiatry. 1978;35:837-44.

[29] Breslau N, Lucia VC, Davis GC. Partial PTSD versus full PTSD: an empirical examination of associated impairment. Psychol Med. 2004;34:1205-14.

[30] Preisig M, Fenton BT, Matthey ML, Berney A, Ferrero F. Diagnostic interview for genetic studies (DIGS): inter-rater and test-retest reliability of the French version. Eur Arch Psychiatry Clin Neurosci. 1999;249:174-9.

[31] Berney A, Preisig M, Matthey ML, Ferrero F, Fenton BT. Diagnostic interview for genetic studies (DIGS): inter-rater and test-retest reliability of alcohol and drug diagnoses. Drug Alcohol Depend. 2002;65:149-58.

[32] Perrin M, Vandeleur CL, Castelao E, Rothen S, Glaus J, Vollenweider P, et al. Determinants of the development of post-traumatic stress disorder, in the general population. Soc Psychiatry Psychiatr Epidemiol. 2013.

[33] McLachlan P, Peel D. Finite mixture models. New York: Wiley; 2000.

[34] Ramaswamy V, Desarbo WS, Reibstein DJ, Robinson WT. An Empirical Pooling Approach for Estimating Marketing Mix Elasticities with Pims Data. Marketing Science. 1993;12:103-24.

[35] Nylund KL, Asparoutiov T, Muthen BO. Deciding on the number of classes in latent class analysis and growth mixture modeling: A Monte Carlo simulation study. Structural Equation Modeling-a Multidisciplinary Journal. 2007;14:535-69.

[36] Muthen LK, Muthen BO. Mplus User's Guide. Sixth Edition ed. Los Angeles, CA: Muthén \& Muthén; 1998-2011.

[37] StataCorp. Stata Statistical Software. Release 13 ed. College Station, TX: StataCorp LP; 2011. 
[38] Cox BJ, Clara IP, Enns MW. Posttraumatic stress disorder and the structure of common mental disorders. Depress Anxiety. 2002;15:168-71.

[39] Morina N, Ajdukovic D, Bogic M, Franciskovic T, Kucukalic A, Lecic-Tosevski D, et al. Co-occurrence of major depressive episode and posttraumatic stress disorder among survivors of war: how is it different from either condition alone? J Clin Psychiatry. 2013;74:e212-8.

[40] Goisman RM, Allsworth J, Rogers MP, Warshaw MG, Goldenberg I, Vasile RG, et al. Simple phobia as a comorbid anxiety disorder. Depress Anxiety. 1998; 7:105-12.

[41] Rytwinski NK, Scur MD, Feeny NC, Youngstrom EA. The co-occurrence of major depressive disorder among individuals with posttraumatic stress disorder: a meta-analysis. J Trauma Stress. 2013;26:299-309.

[42] Norman SB, Trim RS, Goldsmith AA, Dimsdale JE, Hoyt DB, Norman GJ, et al. Role of risk factors proximate to time of trauma in the course of PTSD and MDD symptoms following traumatic injury. J Trauma Stress. 2011;24:390-8.

[43] Miller MW, Fogler JM, Wolf EJ, Kaloupek DG, Keane TM. The internalizing and externalizing structure of psychiatric comorbidity in combat veterans. J Trauma Stress. 2008;21:58-65.

[44] Jaksic N, Brajkovic L, Ivezic E, Topic R, Jakovljevic M. The role of personality traits in posttraumatic stress disorder (PTSD). Psychiatr Danub. 2012;24:256-66.

[45] Mills KL, Teesson M, Ross J, Peters L. Trauma, PTSD, and substance use disorders: findings from the Australian National Survey of Mental Health and Well-Being. Am J Psychiatry. 2006;163:652-8.

[46] Peleg T, Shalev AY. Longitudinal studies of PTSD: overview of findings and methods. CNS Spectr. 2006;11:589-602.

[47] Collimore KC, Carleton RN, Hofmann SG, Asmundson GJ. Posttraumatic stress and social anxiety: the interaction of traumatic events and interpersonal fears. Depress Anxiety. 2010;27:1017-26.

[48] Bandelow B, Koch M, Zimmermann P, Biesold KH, Wedekind D, Falkai P. Posttraumatic stress disorder (PTSD) in the German Armed Forces: a retrospective study in inpatients of a German army hospital. Eur Arch Psychiatry Clin Neurosci. 2012;262:459-67.

[49] Stein MB, Hofler M, Perkonigg A, Lieb R, Pfister H, Maercker A, et al. Patterns of incidence and psychiatric risk factors for traumatic events. Int J Methods Psychiatr Res. 2002;11:143-53.

[50] Tolin DF, Foa EB. Sex differences in trauma and posttraumatic stress disorder: a quantitative review of 25 years of research. Psychol Bull. 2006;132:959-92.

[51] Dore G, Mills K, Murray R, Teesson M, Farrugia P. Post-traumatic stress disorder, depression and suicidality in inpatients with substance use disorders. Drug Alcohol Rev. 2012;31:294-302.

[52] Leeies M, Pagura J, Sareen J, Bolton JM. The use of alcohol and drugs to self-medicate symptoms of posttraumatic stress disorder. Depress Anxiety. 2010;27:731-6.

[53] Engelhard IM, Arntz A, van den Hout MA. Low specificity of symptoms on the post-traumatic stress disorder (PTSD) symptom scale: a comparison of individuals with PTSD, individuals with other anxiety disorders and individuals without psychopathology. Br $\mathrm{J}$ Clin Psychol. 2007;46:449-56.

[54] Zlotnick C, Warshaw M, Shea MT, Allsworth J, Pearlstein T, Keller MB. Chronicity in posttraumatic stress disorder (PTSD) and predictors of course of comorbid PTSD in patients with anxiety disorders. J Trauma Stress. 1999;12:89-100.

[55] Perez Benitez Cl, Zlotnick C, Dyck I, Stout R, Angert E, Weisberg R, et al. Predictors of the long-term course of comorbid PTSD: A naturalistic prospective study. Int J Psychiatry Clin Pract. 2012. 
[56] Breslau N, Davis GC. Posttraumatic stress disorder in an urban population of young adults: risk factors for chronicity. Am J Psychiatry. 1992;149:671-5.

[57] Kerig PK, Ward RM, Vanderzee KL, Arnzen Moeddel M. Posttraumatic stress as a mediator of the relationship between trauma and mental health problems among juvenile delinquents. J Youth Adolesc. 2009;38:1214-25.

[58] Blanco C, Xu Y, Brady K, Perez-Fuentes G, Okuda M, Wang S. Comorbidity of posttraumatic stress disorder with alcohol dependence among US adults: Results from National Epidemiological Survey on Alcohol and Related Conditions. Drug Alcohol Depend. 2013.

[59] Bailey K, Webster R, Baker AL, Kavanagh DJ. Exposure to dysfunctional parenting and trauma events and posttraumatic stress profiles among a treatment sample with coexisting depression and alcohol use problems. Drug Alcohol Rev. 2012;31:529-37.

[60] O'Brien BS, Sher L. Child sexual abuse and the pathophysiology of suicide in adolescents and adults. Int J Adolesc Med Health. 2013:1-5.

[61] Stein MB, Barrett-Connor E. Sexual assault and physical health: findings from a population-based study of older adults. Psychosom Med. 2000;62:838-43.

[62] Darves-Bornoz JM, Delmotte I, Benhamou P, Degiovanni A, Gaillard P. [Syndrome secondary to post-traumatic stress disorder and addictive behaviors]. Ann Med Psychol (Paris). 1996;154:190-4.

[63] Stein MB, Walker JR, Hazen AL, Forde DR. Full and partial posttraumatic stress disorder: findings from a community survey. Am J Psychiatry. 1997:154:1114-9. 


\section{Tables}

Tab 1.

Prevalences of trauma, comorbid conditions and conditional relationships with PTSD

Note: * sum of all considered comorbid conditions excluding suicide attempts;

OR=odds ratio; $95 \% \mathrm{Cl}=95 \%$ confidence interval;

${ }^{5}$ Adjusted for sex and age; significant results are printed in bold

Tab 2.

LCA fit statistics for the tested class solutions

Note: AIC=Akaike Information Criterion, BIC=Bayesian Information Criterion, BLRT=Bootstrapped Likelihood Ratio Test

Tab 3.

Demographic and comorbidity characteristics among the three derived PTSD comorbidity subtypes

Note: * Not including suicide attempts;

$\mathrm{OR}=$ odds ratio; $95 \% \mathrm{Cl}=95 \%$ confidence interval;

Adjusted for sex and age; significant results are printed in bold;

Blank cells indicate that ORs could not be calculated because data were unavailable for this class and therefore comparisons were unfeasible

Tab 4.

Age of onset and temporal associations of PTSD and comorbid disorders among the three comorbidity subtypes of PTSD

Note: $\quad$ age variables $z$-scored;

OR=odds ratio; $95 \% \mathrm{Cl}=95 \%$ confidence interval

${ }^{b}$ Adjusted for sex and age; significant results are printed in bold;

\#1: Onset of alcohol use disorders more likely to succeed PTSD onset in class 2 (versus class 1; OR=6.65; 95\%Cl:1.03-42.98; adjusted for sex and age);

\#2: Onset of unipolar affective disorders less likely to succeed PTSD onset in class 3 (versus class 1; OR=.29; $95 \% \mathrm{Cl}$ : . 11-.76; adjusted for sex and age;

\#3: Onset of phobias more likely to succeed PTSD onset in class 3 (versus class 1 ; OR=2.41; 95\%Cl: 1.05-5.54; adjusted for sex and age) 
Tab 5.

Clinical and trauma features among three derived subtypes of PTSD comorbidity

Note: OR=odds ratio; $95 \% \mathrm{Cl}=95 \%$ confidence interval;

${ }^{\mathrm{b}}$ Adjusted for sex and age; significant results are printed in bold 


\section{Figures}

Fig 1.

Three class solution of PTSD comorbidity

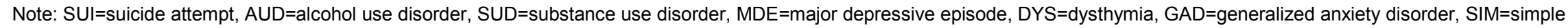
phobia, $\mathrm{SOC}=$ social phobia, $\mathrm{AGO}=$ agora phobia, $\mathrm{PAN}=$ panic disorder, $\mathrm{APD}=$ antisocial personality disorder 
Tab 1.

Prevalences of trauma, comorbid conditions and conditional relationships with PTSD

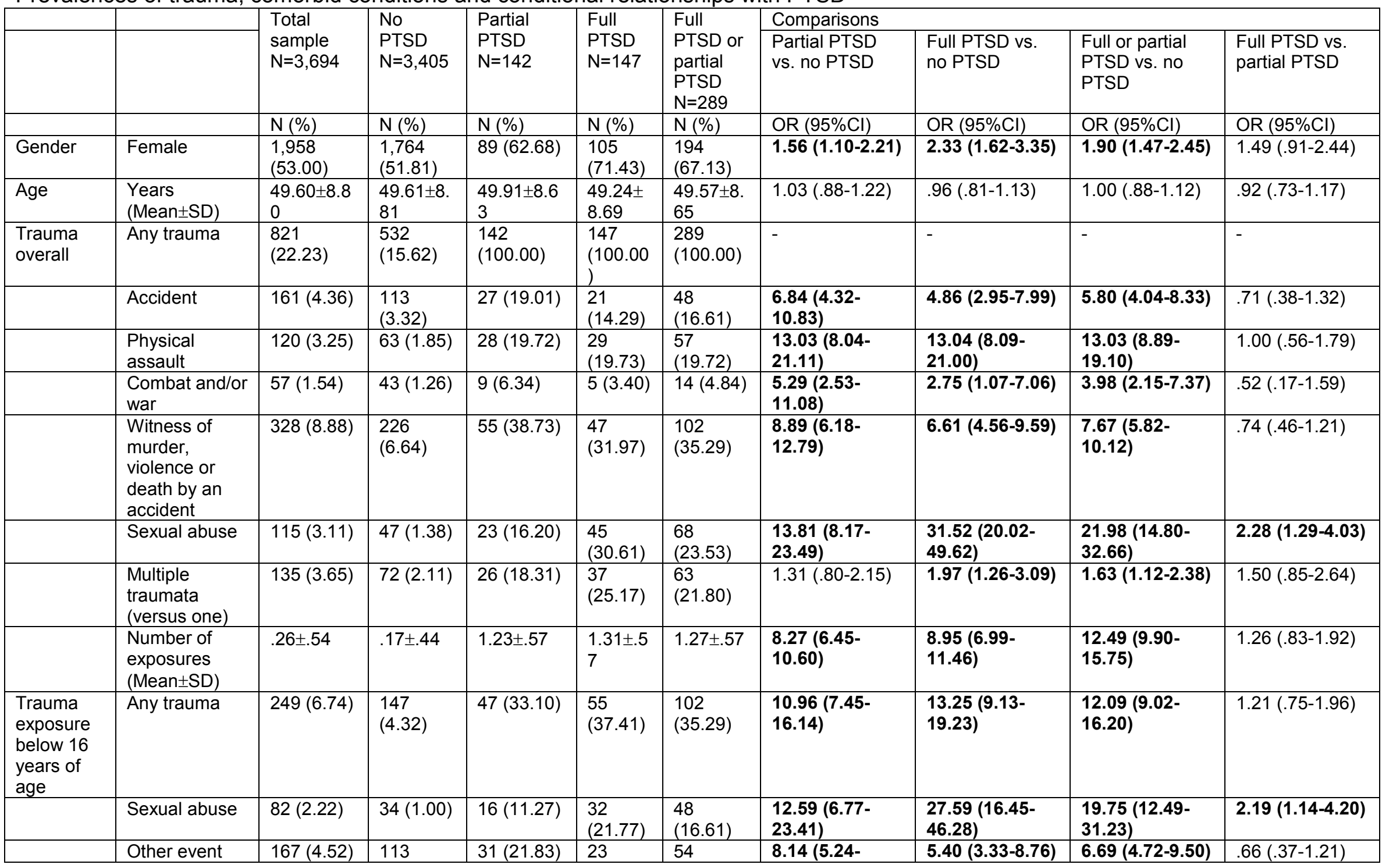




\begin{tabular}{|c|c|c|c|c|c|c|c|c|c|c|}
\hline & & & (3.32) & & $(15.65)$ & $(18.69)$ & 12.63) & & & \\
\hline \multirow[t]{11}{*}{$\begin{array}{l}\text { Comorbid } \\
\text { conditions }\end{array}$} & $\begin{array}{l}\text { Suicide } \\
\text { attempt }\end{array}$ & $219(5.93)$ & $\begin{array}{l}160 \\
(4.70)\end{array}$ & $16(11.27)$ & $\begin{array}{l}43 \\
(29.25)\end{array}$ & $\begin{array}{l}59 \\
(20.42)\end{array}$ & $2.58(1.50-4.44)$ & $\begin{array}{l}8.39(5.68- \\
12.38)\end{array}$ & $5.20(3.75-7.22)$ & $3.26(1.73-6.11)$ \\
\hline & AUD & $\begin{array}{l}434 \\
(11.76)\end{array}$ & $\begin{array}{l}378 \\
(11.11)\end{array}$ & $25(17.61)$ & $\begin{array}{l}31 \\
(21.09)\end{array}$ & $\begin{array}{l}56 \\
(19.38)\end{array}$ & $1.71(1.10-2.67)$ & $2.14(1.42-3.22)$ & $1.92(1.41-2.62)$ & $1.25(.70-2.25)$ \\
\hline & $\begin{array}{l}\text { SUD (w/o } \\
\text { alcohol) }\end{array}$ & $228(6.17)$ & $\begin{array}{l}204 \\
(5.99)\end{array}$ & $9(6.34)$ & $\begin{array}{l}15 \\
(10.20)\end{array}$ & $24(8.30)$ & $1.06(.53-2.12)$ & $1.78(1.03-3.10)$ & $1.42(.91-2.21)$ & $1.68(.71-3.97)$ \\
\hline & $\begin{array}{l}\text { Major } \\
\text { depressive } \\
\text { episode }\end{array}$ & $\begin{array}{l}962 \\
(26.05)\end{array}$ & $\begin{array}{l}866 \\
(25.44)\end{array}$ & $47(33.10)$ & $\begin{array}{l}49 \\
(33.33)\end{array}$ & $\begin{array}{l}96 \\
(33.22)\end{array}$ & $1.45(1.01-2.07)$ & $1.47(1.03-2.08)$ & $1.46(1.13-1.88)$ & $1.01(.62-1.65)$ \\
\hline & Dysthymia & $136(3.68)$ & $\begin{array}{l}116 \\
(3.41)\end{array}$ & $12(8.45)$ & $8(5.44)$ & $20(6.92)$ & $2.62(1.41-4.86)$ & $1.63(.78-3.41)$ & $2.11(1.29-3.44)$ & $.62(.25-1.57)$ \\
\hline & $\begin{array}{l}\text { Generalized } \\
\text { anxiety } \\
\text { disorder }\end{array}$ & $85(2.30)$ & $67(1.97)$ & $2(1.41)$ & $\begin{array}{l}16 \\
(10.88)\end{array}$ & $18(6.23)$ & $.71(.17-2.93)$ & $\begin{array}{l}6.08(3.43- \\
10.78)\end{array}$ & $3.31(1.94-5.65)$ & $\begin{array}{l}8.55(1.93- \\
37.90)\end{array}$ \\
\hline & Simple phobia & $\begin{array}{l}587 \\
(15.90)\end{array}$ & $\begin{array}{l}510 \\
(14.99)\end{array}$ & $44(30.99)$ & $\begin{array}{l}33 \\
(22.45)\end{array}$ & $\begin{array}{l}77 \\
(26.64)\end{array}$ & $2.55(1.76-3.68)$ & $1.64(1.10-2.45)$ & $2.06(1.56-2.72)$ & $.64(.38-1.09)$ \\
\hline & Social phobia & $\begin{array}{l}443 \\
(12.00)\end{array}$ & $\begin{array}{l}378 \\
(11.37)\end{array}$ & $23(16.20)$ & $\begin{array}{l}33 \\
(22.45)\end{array}$ & $\begin{array}{l}56 \\
(19.38)\end{array}$ & $1.51(.95-2.38)$ & $2.26(1.51-3.37)$ & $1.87(1.37-2.56)$ & $1.50(.83-2.70)$ \\
\hline & Agoraphobia & $162(4.39)$ & $\begin{array}{l}138 \\
(4.06)\end{array}$ & $8(5.63)$ & $\begin{array}{l}16 \\
(10.88)\end{array}$ & $24(8.30)$ & $1.41(.68-2.94)$ & $2.89(1.67-4.99)$ & $2.14(1.36-3.36)$ & $2.05(.85-4.94)$ \\
\hline & Panic disorder & $168(4.55)$ & $\begin{array}{l}138 \\
(4.06)\end{array}$ & $9(6.34)$ & $\begin{array}{l}21 \\
(14.38)\end{array}$ & $\begin{array}{l}30 \\
(10.42)\end{array}$ & $1.60(.80-3.21)$ & $3.97(2.43-6.51)$ & $2.75(1.82-4.16)$ & $2.48(1.10-5.63)$ \\
\hline & $\begin{array}{l}\text { Antisocial } \\
\text { personality } \\
\text { disorder }\end{array}$ & $96(2.60)$ & $81(2.38)$ & $3(2.13)$ & $\begin{array}{l}12 \\
(8.22)\end{array}$ & $15(5.23)$ & $.89(.28-2.86)$ & $3.67(1.96-6.90)$ & $2.26(1.29-3.98)$ & $\begin{array}{l}4.12(1.14- \\
14.92)\end{array}$ \\
\hline $\begin{array}{l}\text { Number of } \\
\text { comorbid } \\
\text { conditions* }\end{array}$ & Mean (SD) & $.89 \pm 1.02$ & $.85 \pm .98$ & $1.28 \pm 1.19$ & $\begin{array}{l}1.59 \pm 1 \\
39\end{array}$ & $\begin{array}{l}1.44 \pm 1.3 \\
0\end{array}$ & $1.44(1.25-1.66)$ & $1.72(1.52-1.96)$ & $1.58(1.44-1.75)$ & $1.21(1.00-1.45)$ \\
\hline
\end{tabular}

Tab 2.

LCA fit statistics for the tested class solutions 


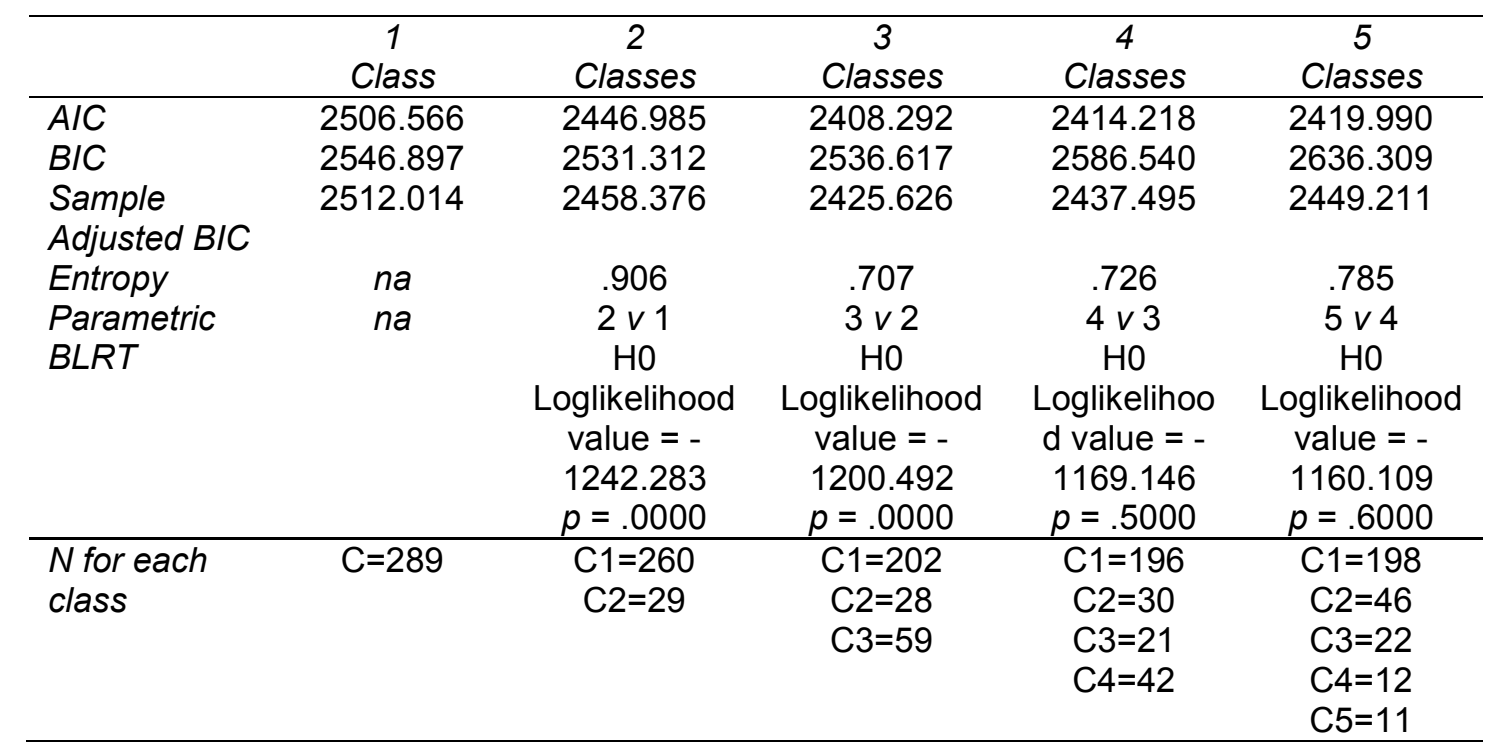

Tab 3.

Demographic and comorbidity characteristics among the three derived PTSD comorbidity subtypes

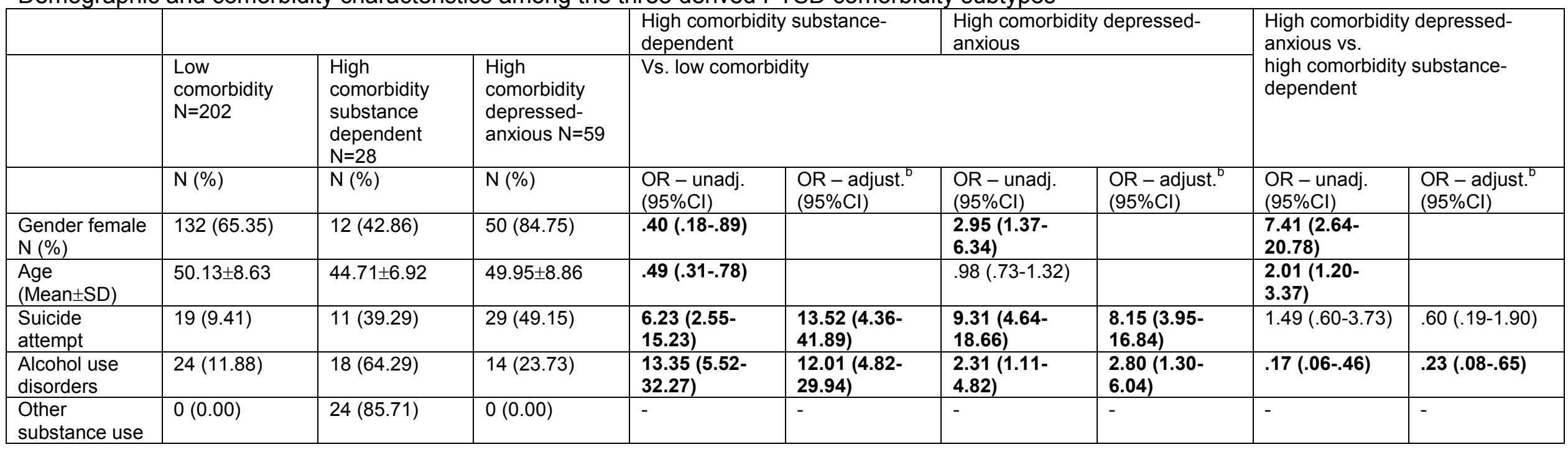




\begin{tabular}{|c|c|c|c|c|c|c|c|c|c|}
\hline disorders & & & & & & & & & \\
\hline $\begin{array}{l}\text { Major } \\
\text { depressive } \\
\text { episode }\end{array}$ & $65(32.18)$ & $10(35.71)$ & 21.35.59) & $1.17(.51-2.68)$ & $.98(.41-2.32)$ & $1.16(.63-2.14)$ & $1.22(.66-2.28)$ & $.99(.39-2.54)$ & $1.25(.47-3.35)$ \\
\hline Dysthymia & $3(1.49)$ & $0(0.00)$ & $17(28.81)$ & - & - & $\begin{array}{l}26.88(7.53- \\
95-91)\end{array}$ & $\begin{array}{l}25.62(7.04- \\
93.17)\end{array}$ & - & - \\
\hline Simple phobia & $32(15.84)$ & $7(25.00)$ & $38(64.41)$ & $1.77(.70-4.51)$ & $1.85(.68-5.00)$ & $\begin{array}{l}9.61(5.00- \\
18.47)\end{array}$ & $\begin{array}{l}8.80(4.51- \\
17.16)\end{array}$ & $\begin{array}{l}5.43(1.98- \\
14.87)\end{array}$ & $\begin{array}{l}4.76(1.61- \\
14.05)\end{array}$ \\
\hline Social phobia & $32(15.84)$ & $3(10.71)$ & $21(35.59)$ & $.64(.18-2.24)$ & $.66(.18-2.39)$ & $\begin{array}{l}2.94(1.53- \\
5.64)\end{array}$ & $\begin{array}{l}2.64(1.36- \\
5.14)\end{array}$ & $\begin{array}{l}4.61(1.24- \\
17.08)\end{array}$ & $\begin{array}{l}4.00(1.03- \\
15.51)\end{array}$ \\
\hline Agoraphobia & $0(0.00)$ & $4(14.29)$ & $20(33.90)$ & - & - & - & - & $\begin{array}{l}3.08(.94- \\
10.10)\end{array}$ & $1.97(.55-7.08)$ \\
\hline $\begin{array}{l}\text { Generalized } \\
\text { anxiety } \\
\text { disorder }\end{array}$ & $3(1.49)$ & $0(0.00)$ & $15(25.42)$ & - & - & $\begin{array}{l}22.62 \text { (6.28- } \\
81.54)\end{array}$ & $\begin{array}{l}22.05(6.01- \\
80.96)\end{array}$ & - & - \\
\hline Panic disorder & $4(1.98)$ & $6(22.22)$ & $20(33.90)$ & $\begin{array}{l}14.14 \text { (3.69- } \\
54.16)\end{array}$ & $\begin{array}{l}11.89(2.99- \\
47.32)\end{array}$ & $\begin{array}{l}25.38(8.22- \\
78.35)\end{array}$ & $\begin{array}{l}26.58(8.37- \\
84.48)\end{array}$ & $1.79(.62-5.16)$ & $2.24(.69-7.29)$ \\
\hline $\begin{array}{l}\text { Antisocial } \\
\text { personality } \\
\text { disorder }\end{array}$ & $1(0.50)$ & $14(50.00)$ & $0(0.00)$ & $\begin{array}{l}199.91(24.49- \\
1631.81)\end{array}$ & $\begin{array}{l}212.66(23.83- \\
1898.03)\end{array}$ & - & - & - & - \\
\hline $\begin{array}{l}\text { Number of } \\
\text { comorbid } \\
\text { conditions * } \\
\text { (Mean } \pm \text { SD) }\end{array}$ & $.81 \pm .75$ & $3.07 \pm 1.33$ & $2.81 \pm 1.03$ & $\begin{array}{l}17.94(8.33- \\
38.65)\end{array}$ & $\begin{array}{l}19.16(8.55- \\
42.95)\end{array}$ & $\begin{array}{l}14.73(7.24- \\
29.98)\end{array}$ & $\begin{array}{l}16.32 \text { (7.78- } \\
34.23)\end{array}$ & $.82(.55-1.22)$ & $.85(.54-1.35)$ \\
\hline
\end{tabular}

Tab 4.

Age of onset and temporal associations of PTSD and comorbid disorders among the three comorbidity subtypes of PTSD

\begin{tabular}{|c|c|c|c|c|c|c|c|c|c|}
\hline & & & & $\begin{array}{l}\text { High com } \\
\text { substanc }\end{array}$ & $\begin{array}{l}\text { idity } \\
\text { ependent }\end{array}$ & $\begin{array}{l}\text { High comorb } \\
\text { depressed-a }\end{array}$ & $\begin{array}{l}\text { ty } \\
\text { ious }\end{array}$ & \multirow{2}{*}{\multicolumn{2}{|c|}{$\begin{array}{l}\text { High comorbidity } \\
\text { depressed-anxious vs. } \\
\text { high comorbidity } \\
\text { substance-dependent }\end{array}$}} \\
\hline & $\begin{array}{l}\text { Low } \\
\text { comorbidity } \\
\mathrm{N}=202\end{array}$ & $\begin{array}{l}\text { High } \\
\text { comorbidity } \\
\text { substance } \\
\text { dependent } \\
\mathrm{N}=28\end{array}$ & $\begin{array}{l}\text { High } \\
\text { comorbidity } \\
\text { depressed- } \\
\text { anxious } \mathrm{N}=59\end{array}$ & \multicolumn{4}{|c|}{ Vs. low comorbidity } & & \\
\hline & $\mathrm{N}(\%)$ & $\mathrm{N}(\%)$ & $\mathrm{N}(\%)$ & $\begin{array}{l}\text { OR - } \\
\text { unadj. } \\
(95 \% \mathrm{Cl})\end{array}$ & $\begin{array}{l}\text { OR - } \\
\text { adjust. }{ }^{b} \\
(95 \% \mathrm{Cl})\end{array}$ & $\begin{array}{l}\text { OR - } \\
\text { unadj. } \\
(95 \% \mathrm{Cl})\end{array}$ & $\begin{array}{l}\text { OR - } \\
\text { adjust. }^{b} \\
(95 \% \mathrm{CI})\end{array}$ & $\begin{array}{l}\text { OR - } \\
\text { unadj. } \\
(95 \% \mathrm{Cl})\end{array}$ & $\begin{array}{l}\text { OR - } \\
\text { adjust. }^{b} \\
(95 \% \mathrm{Cl})\end{array}$ \\
\hline $\begin{array}{l}\text { Age of PTSD onset } \\
(\text { Mean } \pm \text { SD) }\end{array}$ & $23.48 \pm 14.37$ & $\begin{array}{l}19.00 \pm 11.1 \\
2\end{array}$ & $25.27 \pm 15.45$ & $\begin{array}{l}.70(.45- \\
1.10)\end{array}$ & $\begin{array}{l}.66(.39- \\
1.11)\end{array}$ & $\begin{array}{l}1.13(.85- \\
1.50)\end{array}$ & $\begin{array}{l}1.19(.89- \\
1.59)\end{array}$ & $\begin{array}{l}1.61(.98- \\
2.64)\end{array}$ & $\begin{array}{l}1.80(1.02- \\
3.18)\end{array}$ \\
\hline $\begin{array}{l}\text { Age of AUD onset } \\
(\text { Mean } \pm S D) \# 1\end{array}$ & $31.56 \pm 11.87$ & $24.47 \pm 7.69$ & $37.85 \pm 15.69$ & $\begin{array}{l}.46(.21- \\
1.00)\end{array}$ & $\begin{array}{l}.58(.24- \\
1.43)\end{array}$ & $\begin{array}{l}1.47(.84- \\
2.55)\end{array}$ & $\begin{array}{l}1.80(.78- \\
4.14)\end{array}$ & $\begin{array}{l}3.18(1.37- \\
7.40)\end{array}$ & $\begin{array}{l}3.10(1.01- \\
9.52)\end{array}$ \\
\hline $\begin{array}{l}\text { Age of SUD onset } \\
\text { (Mean } \pm \text { SD) }\end{array}$ & - & $21.09 \pm 5.02$ & - & - & - & - & - & - & - \\
\hline Age of major depression & $37.19 \pm 12.12$ & $29.80 \pm 19.6$ & $36.33 \pm 13.07$ & .61 (.34- & $.61(.31-$ & .94 (.66- & $1.12(.51-$ & $1.54(.79-$ & $1.82(.81-$ \\
\hline
\end{tabular}




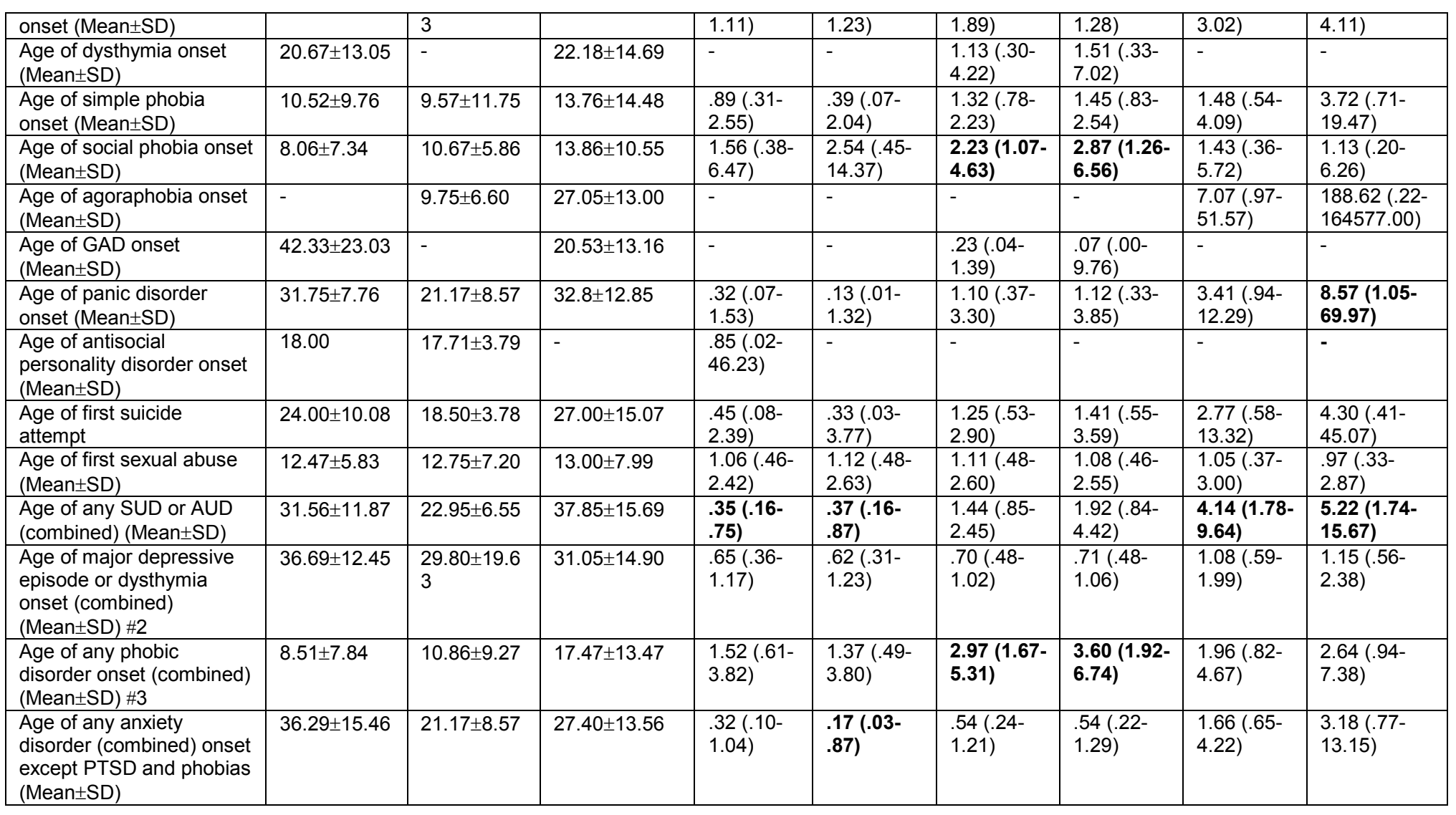

Tab 5.

Clinical and trauma features among three derived subtypes of PTSD comorbidity

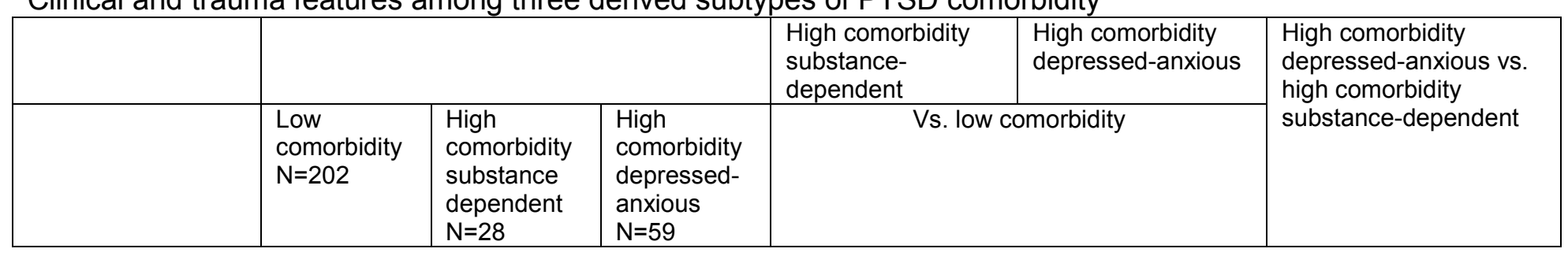




\begin{tabular}{|c|c|c|c|c|c|c|c|c|c|}
\hline & $\mathrm{N}(\%)$ & $\mathrm{N}(\%)$ & $\mathrm{N}(\%)$ & $\begin{array}{l}\text { OR - } \\
\text { unadj. } \\
(95 \% \mathrm{Cl})\end{array}$ & $\begin{array}{l}\text { OR - } \\
\text { adjust. }^{\text {b }} \\
(95 \% \mathrm{Cl})\end{array}$ & $\begin{array}{l}\text { OR - } \\
\text { unadj. } \\
(95 \% \mathrm{Cl})\end{array}$ & $\begin{array}{l}\text { OR - } \\
\text { adjust. }^{\text {b }} \\
(95 \% \mathrm{Cl})\end{array}$ & $\begin{array}{l}\text { OR - } \\
\text { unadj. } \\
(95 \% \mathrm{Cl})\end{array}$ & $\begin{array}{l}\text { OR - } \\
\text { adjust. }^{\text {b }} \\
(95 \% \mathrm{Cl})\end{array}$ \\
\hline $\begin{array}{l}\text { PTSD - re- } \\
\text { experience } \\
\text { symptoms }\end{array}$ & $3.11 \pm 1.33$ & $3.68 \pm 1.31$ & $3.58 \pm 1.42$ & $\begin{array}{l}1.38 \\
(1.01- \\
1.89)\end{array}$ & $\begin{array}{l}1.41 \\
(1.01- \\
1.97)\end{array}$ & $\begin{array}{l}1.30 \\
(1.04- \\
1.63)\end{array}$ & $\begin{array}{l}1.26 \\
(1.01- \\
1.58)\end{array}$ & $\begin{array}{l}.94(.66- \\
1.34)\end{array}$ & $\begin{array}{l}.89(.61- \\
1.30)\end{array}$ \\
\hline $\begin{array}{l}\text { PTSD - } \\
\text { avoidance/numbing } \\
\text { symptoms }\end{array}$ & $3.31 \pm 1.65$ & $4.21 \pm 1.93$ & $4.20 \pm 1.76$ & $\begin{array}{l}1.35 \\
(1.08- \\
1.70)\end{array}$ & $\begin{array}{l}1.46 \\
(1.14- \\
1.87)\end{array}$ & $\begin{array}{l}1.35 \\
(1.14- \\
1.60)\end{array}$ & $\begin{array}{l}1.30 \\
(1.09- \\
1.54)\end{array}$ & $\begin{array}{l}1.00(.77- \\
1.29)\end{array}$ & $\begin{array}{l}.89(.67- \\
1.17)\end{array}$ \\
\hline $\begin{array}{l}\text { PTSD - } \\
\text { hyperarousal } \\
\text { symptoms }\end{array}$ & $2.53 \pm 1.22$ & $2.75 \pm 1.24$ & $3.19 \pm 1.18$ & $\begin{array}{l}1.16 \\
(.84- \\
1.60) \\
\end{array}$ & $\begin{array}{l}1.28 \\
(.91- \\
1.80) \\
\end{array}$ & $\begin{array}{l}1.53 \\
(1.20- \\
1.94) \\
\end{array}$ & $\begin{array}{l}1.46 \\
(1.15- \\
1.86) \\
\end{array}$ & $\begin{array}{l}1.32(.92- \\
1.89)\end{array}$ & $\begin{array}{l}1.14(.77- \\
1.67)\end{array}$ \\
\hline $\begin{array}{l}\text { Last month GAF } \\
\text { score }\end{array}$ & $73.78 \pm 15.93$ & $59.5 \pm 19.59$ & $56.31 \pm 14.62$ & $\begin{array}{l}.48(.34- \\
.68)\end{array}$ & $\begin{array}{l}.41(.28- \\
.60)\end{array}$ & $\begin{array}{l}.48 \\
(.37- \\
.63) \\
\end{array}$ & $\begin{array}{l}.50(.38- \\
.66)\end{array}$ & $\begin{array}{l}.99(.68- \\
1.43)\end{array}$ & $\begin{array}{l}1.23(.81- \\
1.87)\end{array}$ \\
\hline Accident & $31(15.35)$ & $6(21.43)$ & $11(18.64)$ & $\begin{array}{l}1.50 \\
(.56- \\
4.01)\end{array}$ & $\begin{array}{l}1.22 \\
(.44- \\
3.38)\end{array}$ & $\begin{array}{l}1.26 \\
(.59- \\
2.70)\end{array}$ & $\begin{array}{l}1.35 \\
(.62- \\
2.94)\end{array}$ & $\begin{array}{l}.84(.28- \\
2.56)\end{array}$ & $\begin{array}{l}1.11(.34- \\
3.60)\end{array}$ \\
\hline Physical assault & $42(20.79)$ & $1(3.57)$ & $14(23.73)$ & $\begin{array}{l}.14(.02- \\
1.07)\end{array}$ & $\begin{array}{l}.15(.02- \\
1.14)\end{array}$ & $\begin{array}{l}1.19 \\
(.59- \\
2.36)\end{array}$ & $\begin{array}{l}1.19 \\
(.59- \\
2.40)\end{array}$ & $\begin{array}{l}8.40 \\
(1.05- \\
67.51)\end{array}$ & $\begin{array}{l}8.03(.97- \\
66.48)\end{array}$ \\
\hline Combat and/or war & $11(5.45)$ & $2(7.14)$ & $1(1.69)$ & $\begin{array}{l}1.34 \\
(.28- \\
6.36) \\
\end{array}$ & $\begin{array}{l}1.11 \\
(.21- \\
5.83) \\
\end{array}$ & $\begin{array}{l}30 \\
(.04- \\
2.37) \\
\end{array}$ & $\begin{array}{l}.48(.06- \\
4.01)\end{array}$ & $\begin{array}{l}.22(.02- \\
2.58)\end{array}$ & $\begin{array}{l}.44(.03- \\
5.62)\end{array}$ \\
\hline $\begin{array}{l}\text { Witness of murder, } \\
\text { violence or death } \\
\text { by an accident }\end{array}$ & $73(36.14)$ & $7(25.00)$ & $22(37.29)$ & $\begin{array}{l}.59(.24- \\
1.45)\end{array}$ & $\begin{array}{l}.50(.19- \\
1.28)\end{array}$ & $\begin{array}{l}1.05 \\
(.58- \\
1.92)\end{array}$ & $\begin{array}{l}1.19 \\
(.64- \\
2.21)\end{array}$ & $\begin{array}{l}1.78(.65- \\
4.87)\end{array}$ & $\begin{array}{l}2.39(.83- \\
6.93)\end{array}$ \\
\hline Sexual abuse & $45(22.28)$ & $12(42.86)$ & $11(18.64)$ & $\begin{array}{l}2.62 \\
(1.15- \\
5.93)\end{array}$ & $\begin{array}{l}6.02 \\
(2.03- \\
17.85)\end{array}$ & $\begin{array}{l}.80 \\
(.38- \\
1.67)\end{array}$ & $\begin{array}{l}.59(.27- \\
1.25)\end{array}$ & $\begin{array}{l}.31(.11- \\
.83)\end{array}$ & $\begin{array}{l}.10(.03- \\
.34)\end{array}$ \\
\hline $\begin{array}{l}\text { Number of trauma } \\
\text { exposure } \\
\text { (Mean } \pm S D \text { ) }\end{array}$ & $1.25 \pm .56$ & $1.32 \pm .61$ & $1.31 \pm .59$ & $\begin{array}{l}1.22 \\
(.64- \\
2.33)\end{array}$ & $\begin{array}{l}1.05 \\
(.53- \\
2.09)\end{array}$ & $\begin{array}{l}1.17 \\
(.72- \\
1.92)\end{array}$ & $\begin{array}{l}1.34 \\
(.80- \\
2.24)\end{array}$ & $\begin{array}{l}.96(.46- \\
1.98)\end{array}$ & $\begin{array}{l}1.28(.58- \\
2.82)\end{array}$ \\
\hline $\mathrm{CH}-A n y$ trauma & $72(35.64)$ & $11(39.29)$ & $19(32.20)$ & $\begin{array}{l}1.17 \\
(.52- \\
2.63)\end{array}$ & $\begin{array}{l}1.26 \\
(.53- \\
2.98)\end{array}$ & $\begin{array}{l}86 \\
(.46- \\
1.59)\end{array}$ & $\begin{array}{l}.73(.39- \\
1.38)\end{array}$ & $\begin{array}{l}.73(.29- \\
1.87)\end{array}$ & $\begin{array}{l}.58(.21- \\
1.57)\end{array}$ \\
\hline Child CSA & $33(16.34)$ & $8(28.57)$ & $7(11.86)$ & $\begin{array}{l}2.05 \\
(.83- \\
5.04)\end{array}$ & $\begin{array}{l}3.61 \\
(1.24- \\
10.46)\end{array}$ & $\begin{array}{l}.69 \\
(.29- \\
1.65)\end{array}$ & $\begin{array}{l}.53(.22- \\
1.29)\end{array}$ & $\begin{array}{l}.34(.11- \\
1.05)\end{array}$ & $\begin{array}{l}.15(.04- \\
.53)\end{array}$ \\
\hline $\mathrm{CH}$-Other event & 39 (19.31) & $3(10.71)$ & $12(20.34)$ & $\begin{array}{l}.50(.14- \\
1.75)\end{array}$ & $\begin{array}{l}.39(.11- \\
1.43)\end{array}$ & $\begin{array}{l}1.07 \\
(.52- \\
2.20)\end{array}$ & $\begin{array}{l}1.11 \\
(.53- \\
2.31)\end{array}$ & $\begin{array}{l}2.13(.55- \\
8.25)\end{array}$ & $\begin{array}{l}2.82(.68- \\
11.68)\end{array}$ \\
\hline
\end{tabular}




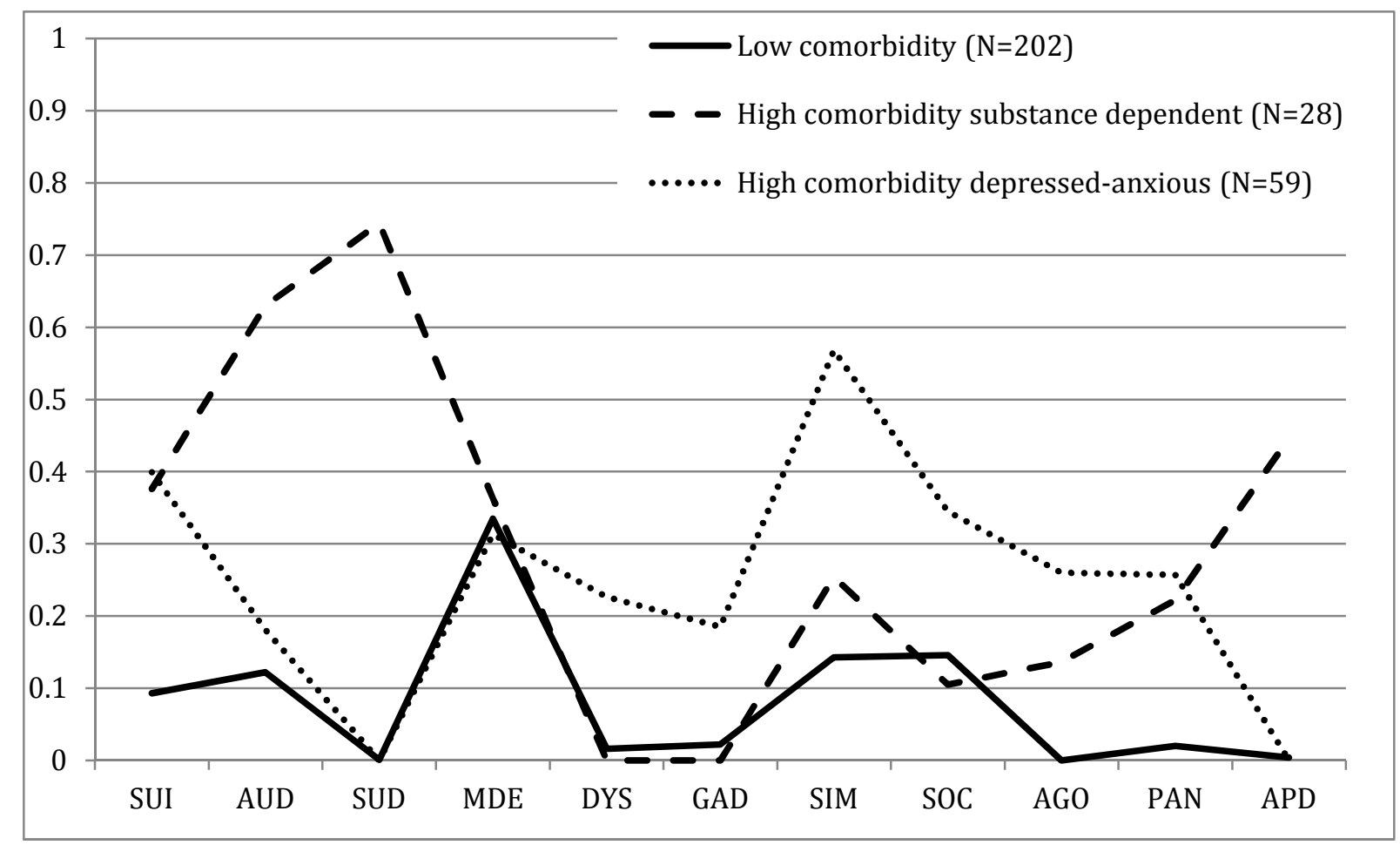

Fig 1.

Three class solution of PTSD comorbidity 